\title{
Publish or perish: o papel dos periódicos científicos
}

\footnotetext{
Ta edição n. 435 do "Jornal da Ciência", editado pela Socieda de Brasileira para o Progresso da Ciência, Castro e Parentoni (2000) fazem a seguinte indagação:
}

Valerá a pena perseguirmos a todo custo a meta de um grande número
de publicações, deixando de lado os valores humanos e sociais que nos
proporcionam uma visão de mundo abrangente e atenta às diferenças
que o distinguem e enriquecem? (p. 9).

Tais autores atribuem à absorção de modismos internacionais, no caso, da máxima publish or perish, a compulsão por publicações pouco criativas, "contendo conhecimento repetitivo e monótono" (p. 9), em detrimento de uma produção de alta qualidade.

Trata-se, sem dúvida, de uma questão tão importante quanto polêmica, que merece a atenção daqueles envolvidos com pesquisa, pósgraduação e editoração científica.

Admitindo, liminarmente, a complexidade da questão, gostaria de tocar em algumas questões.

Em primeiro lugar, a da mensuração da produção científica. Nunca é demais lembrar que estamos em um terreno especializado, campo internacionalmente consagrado de estudos, traduzido em disciplinas como cienciometria, bibliometria e a informetria (Macias-Chapula, 1998; Spinak, 1998; Trzesniak, 1998).

O número de trabalhos é apenas um dos indicadores para a monitoração da produção de conhecimento. A co-autoria, índice de colaboração entre pesquisadores em nível nacional ou internacional 
e, sobretudo, o número de citações, refletindo o impacto dos trabalhos são outros desses indicadores.

Conquanto parâmetros importantes, também não há consenso acerca da capacidade de medir os avanços científicos. Nos encontros de pesquisadores da Psicologia no Brasil, raras são as oportunidades em que não se lembra que os autores brasileiros preferem citar seus colegas do exterior que os do seu departamento ou de outras instituições nacionais. Fruto de desconhecimento do que os pesquisadores brasileiros fazem pela precariedade do nosso sistema de recuperação de informações científicas ou reflexo de colonialismo cultural, a verdade é que isso somente agrava uma tendência de consagrar a produção daquelas nações com maior desenvolvimento científico-econômico que já, por si só, desenvolvem estratégias de incremento do impacto através de estratégias de citações por razões não somente científicas, mas pessoais e políticas (ver Gibbs, 1995; Macias-Chapula, 1998, entre outros).

Por essas e outras razões, há uma rejeição dentre os pesquisadores de um processo de avaliação através de um sistema quantitativo, defendendo a avaliação por pares como alternativa (Macias-Chapula, 1998).

Isto nos remete para a segunda questão. Macias-Chapula (1998), retomando as teses de Cronin, lembra que o processo de citação é controlado por quatro grupos: os educadores (professores universitários e orientadores), os consumidores (leitores e membros da comunidade científica), os produtores (pesquisadores) e os "controladores de qualidade". Estes - considerados os "guardiões da comunidade científica” (p. 137) seriam os editores de revistas, os consultores e membros de conselhos das publicações.

Se tiver procedência tal categorização, a nossa responsabilidade é terrível! Retomando a questão acima posta, no processo de publicação de periódicos científicos (assim como na avaliação de programas de pós-graduação, outro dos pontos que nos tocam), a avaliação por pares constitui-se em um elemento central. Mas, longe de "resolver" a questão, o estabelecimento de um sistema competente de arbitragem é um terreno extremamente movediço. Pessanha (1998), discutindo 
essa questão, levanta mais de uma dezena de itens que podem se constituir em conduta antiética de autores, pareceristas, editores, assistentes editoriais e equipe editorial (indo desde a falsificação de dados, emissão de parecer mentiroso, até o roubo de idéias por um parecerista ou editor), que mostram a complexidade de um processo de arbitragem isento e de qualidade.

A terceira questão que gostaria de abordar diz respeito à decisão de publicar. Prieto e Avila (1994), avaliando aspectos da Psicologia desenvolvida na Espanha, ironizam o "produtivismo" dos pesquisadores espanhóis, afirmando que, à Dom Quixote, seus conterrâneos consideram que as suas idéias, transpostas para o papel, tornam-se realidade.

Se tal crítica, que se aproxima daquela citada anteriormente no caso brasileiro (Castro \& Parentoni, 2000), pode ter procedência, coloca-nos diante de um dilema: não ensinamos em nossos cursos de Metodologia Científica, que ciência é um empreendimento coletivo; que a investigação científica nasce no contato do pesquisador com a realidade e somente se realiza com a divulgação dos resultados?

Ademais, tomando como pressuposto que, virtualmente, a totalidade da pesquisa no Brasil é feita em instituições públicas, com recursos de agências de fomento estatais, não seria um compromisso a publicação, para expor nosso trabalho à crítica externa?

Mais ainda, sabendo que, conforme De Meis (1996), 40\% dos conhecimentos gerados a cada ano nos Estados Unidos não são publicados por razões econômicas ou estratégicas, propugnar pelo acesso à informação não se constitui em uma tarefa alinhada com os preceitos democráticos?

Se tudo isso é verdade, estamos de volta às nossas indagações iniciais. Se, por um lado, impõe-se ao pesquisador expor suas idéias, não somente pelo fato de a comunicação se constituir em uma das condições para o avanço do conhecimento, mas também pelo compromisso social envolvido, por outro, nada justificaria a publicação de uma imensa quantidade de trabalhos "repetitivos e monótonos". Novamente, a responsabilidade de publicar ou não dependeria de uma avaliação dos "controladores de qualidade" - recolocando todos os problemas já referidos. 
Finalmente, gostaria de levantar a questão das demandas para a produção. O monitoramento da produção científica, como se sabe, é uma tarefa levada a sério, sobretudo pelos países economicamente mais desenvolvidos. Tal processo tem, como uma de suas motivações fundamentais, a avaliação do desempenho científico de uma nação com vistas ao cumprimento de metas econômicas e estratégicas estabelecidas pelo Estado. Com base nesse sistema de informações, definições concernentes à política científica podem ser traçadas.

Nada nos poderia fazer supor que seria diferente com relação às agências de fomento no Brasil. No caso do $\mathrm{CNPq}$, a pressão para o incremento da produção como condição para concessão de auxílios e bolsas fica patente com a mudança da denominação de bolsa de pesquisa para "produtividade em pesquisa". Na CAPES, o item de maior peso na avaliação dos programas de pós-graduação é a produção científica (Macedo \& Menandro, 1998).

A equação parece completa, dessa forma. Se estabelecida a tendência de privilégio ao financiamento através de indução que ao atendimento da demanda espontânea, os pesquisadores mais produtivos que atuam nas áreas definidas como estratégicas seriam amplamente favorecidos com relação a outros, cujas definições considerassem critérios diversos de prioridade.

Contudo, política, conforme lembra Abranches (1989), não é contrato mas conflito. Tanto a alocação de recursos quanto a definição de prioridades é fruto de uma correlação de forças, em um jogo do qual tomam parte tanto entidades científicas, quanto a própria comunidade científica, através de seus representantes.

Para que possamos, nesse jogo desigual, fazer prevalecer definições que, conforme Castro e Parentoni (2000), considerem os valores humanos e sociais, é fundamental que a comunidade científica tenha um papel mais agressivo e participante no processo de escolha dos representantes e no acompanhamento das suas ações nos diversos organismos do Estado.

Nessa direção, não seria conveniente colocar em discussão algumas das definições que têm norteado nosso sistema de C\&T? Levanto, apenas para referência, questões como o papel dos chamados "mes- 
trados profissionalizantes" no IV PNPG; a exigência, sempre crescente, de diminuição do tempo de qualificação, uniformizando áreas e situações absolutamente díspares; a pesquisa superficial e rápida em detrimento daquela, mais criativa e consistente e, potencialmente, menos vantajosa em termos de produtos quantificáveis; dentre tantos aspectos.

Para finalizar, no que tange à questão que nos acompanhou nesse percurso, enquanto não colocarmos a discussão acerca do "produtivismo" em outros patamares, a responsabilidade dos editores, consultores e equipes das revistas será dobrada. Em outras palavras, a pressão pela produção sempre fará com que a decisão do que publicar seja transferida do autor para a revista - esse é o dilema do editor (Greene, 1998) ${ }^{1}$.

Este fascículo, com o qual iniciamos o nosso quinto ano de existência, traz as contribuições de Jane Correa em uma pesquisa sobre o entendimento intuitivo de crianças da divisão partitiva de quantidades contínuas; de José Angel V. Noriega, pesquisador do Centro de Investigación en Alimentación y Desarrollo do México, em um trabalho sobre avaliação de um programa de merendas escolares; de Maria da Graça B. Borges Dias, Arne Vikan e Sissel Gravås, em um estudo sobre regulação de emoções em crianças; de Alessandra M. Cecconello e Sílvia H. Koller investigando o tema competência social e empatia; de Magda Dimenstein, discutindo questões vinculadas ao profissional de Psicologia no campo da saúde; de Reinaldo Furlan, em um trabalho sobre a natureza e economia na teoria freudiana; de Edwiges F. M. Silvares, avaliando uma experiência inovadora de atendimento em clínica-escola; José G. Medeiros e Sonia A. Teixeira apresentando um estudo sobre o ensino de leitura e escrita através do pareamento com o modelo; e Fernando Aguiar discutindo as relações entre a Psicologia Clínica e a Psicanálise na França.

Na sessão de Comunicações Breves, os temas da maternidade na adolescência (Verônica de S. Pinheiro) e da relação entre Psicologia Escolar e Psicopedagogia (Margareth R. B. Lima Jucá) são discutidos.

Finalmente, Maria Emília Yamamoto resenha as polêmicas teses de Jared Diamond em "Por que o sexo é divertido?". 
Este conjunto é fruto dos nossos dilemas, autores, consultores, equipe e editor - que desejamos compartilhar com os leitores, na expectativa de termos cumprido nosso papel: dar visibilidade a trabalhos de qualidade.

Oswaldo H. Yamamoto

Editor

\section{Referências}

Abranches, S. H. (1989). Política social e combate à pobreza: a teoria da prática. In S. Abranches, W. G. Santos \& M. A. Coimbra (Orgs.), Política social e combate à pobreza ( 2 ' ed., pp. 9-31). Rio de Janeiro, Jorge Zahar.

Castro, M. C. L., \& Parentoni, R. (2000). Viver sob a pressão dos papers? Jornal da Ciência, XIV(435), 9.

De Meis, L., \& Leta, J. (1996). O perfil da ciência brasileira. Rio de Janeiro: Editora da UFRJ.

Gibbs, W. W. (1995). Lost science in the Third World. Scientific American, August, 76-83.

Greene, L. J. (1998). O dilema do editor de uma revista biomédica: aceitar ou não aceitar. Ciência da Informação, 27(2), 230-232.

Macedo, L. de, \& Menandro, P. R. M. (1998). Considerações sobre os indicadores de produção no processo de avaliação dos programas de pós-graduação em Psicologia. Infocapes, 6(3), 34-38.

Macias-Chapula, C. A. (1998). O papel da informetria e da cienciometria e sua perspectiva nacional e internacional. Ciência da Informação, 27(2), 134-140.

Pessanha, C. (1998). Critérios editoriais de avaliação científica: notas para discussão. Ciência da Informação, 27(2), 226-229.

Prieto, J. M., \& Avila, A. (1994). Linking certified knowledge to labour markets. Applied Psychology: An International Review, 43(2), 113-130.

Spinak, E. (1998). Indicadores cienciometricos. Ciência da Informação, 27(2), 141-148.

Trzesniak, P. (1998). Indicadores quantitativos: reflexões que antecedem seu estabelecimento. Ciência da Informação, 27(2), 159-164.

Yamamoto, O. H., Koller, S. H., Guedes, M. C., LoBianco, A. C., Sá, C. P. de, Hutz, C. S., Bueno, J. L. O., Macedo, L. de, \& Menandro, P. R. M. (1999). Periódicos científicos em Psicologia: uma proposta de avaliação. Infocapes, 6(3), 7-13. 
1 Para que a produção científica de uma área não se transforme em uma "ditadura dos editores", é indispensável que essas publicações sejam avaliadas de maneira rigorosa, seus critérios de arbitragem transparentes. Uma dessas tentativas está sendo feita, como é do conhecimento dos pesquisadores da Psicologia, pela ANPEPP em conjunto com a CAPES (Yamamoto et al., 1999). Na tentativa de expor o trabalho à crítica, esse sistema (apenas o primeiro passo) tem sido avaliado por especialistas do campo das Ciências da Informação, visando seu aprimoramento. 